\section{SYMPATHECTOMY FOR HYPERTENSION}

\section{FOLLOW-UP OF 212 PATIENTS}

BY

\author{
C. P. NEWCOMBE, M.D., M.R.C.P. \\ Senior Medical Registrar, General Infirmary, Leeds
}

H. S. SHUCKSMITH, T.D., M.B., B.Sc., F.R.C.S. Surgeon, General Infirmary, Leeds

AND

\section{W. S. SUFFERN, M.D., M.R.C.P. Physician, Keighley Victoria Hospital}

This paper sets out to describe and discuss the results of sympathectomy in 212 patients suffering from hypertension. The operations were performed during the period 1947 to 1953 inclusive. The follow-up has been conducted since 1950 by two senior medical registrars virtually independent of the surgeon. The assessments made were therefore unbiased by enthusiasm for a particular surgical method.

The blood-pressure readings given throughout the paper were obtained from the resting out-patient. The lowest diastolic reading indicative of hypertension was arbitrarily fixed at $110 \mathrm{~mm}$. $\mathrm{Hg}$. Pre-operative bloodpressure readings exceeded $120 \mathrm{~nm} . \mathrm{Hg}$ in $80 \%$, and $140 \mathrm{~mm}$. $\mathrm{Hg}$ in $45 \%$, of the patients. In $27 \%$ sympathectomy reduced the diastolic pressure by $20-50$ $\mathrm{mm}$. $\mathrm{Hg}$ and maintained it at this lower level. Changes in blood pressure are the simplest and most convenient measurements to use in judging the effect of treatment, and on this count the results in this series show considerable benefit; but when the more important subjective improvement is also considered, and the general well-being and the increasingly useful lives led by many of the patients for some years after the operation are realized, even though the initial fall in blood pressure may not have been maintained, then a more balanced view of the improvement after sympathectomy is obtained. Some of the recoveries have been dramatic, as, for example, that of a male telephone operator previously blind as a result of hypertensive encephalopathy, who could barely discern the figure of a man a few days after unilateral sympathectomy but 10 years later could still see to do full work, and whose blood pressure remained much reduced. Forty sympathectomies for hypertension have been performed since 1953, and the results continue to indicate that the method is of value.

\section{Pre-operative Management and Selection}

In an endeavour to find any of the known causes of hypertension, a full clinical assessment was made of every patient with special attention to any renal cause or evidence of phaeochromocytoma. For the purpose of comparison with the results published by other workers, and so that these results can be compared with other methods of treatment, the criteria of Wagener and Keith (1939) in grading the optic fundi 1 to 4, and the grouping of the patients 1 to 4 in the manner adopted by Palmer et al. (1948), are used. Additional special tests were found to be of no help in reaching a decision on the probable advantage or otherwise of employing sympathectomy.
The operation was performed on those patients whose diastolic blood pressure was raised to more than 110 $\mathrm{mm}$. $\mathrm{Hg}$, and whose symptoms were caused by hypertension, provided that they had not suffered a cardiac infarct or cerebral thrombosis during the past three months and the urea clearance was not less than $20 \%$. All patients with grade 4 fundi, papilloedema, and exudates were subjected to operation unless the blood urea nitrogen was greater than $100 \mathrm{mg}$. per $100 \mathrm{ml}$.

\section{Surgical Analysis}

The extent of the sympathectomy used varied according to the recognized established procedures. (1) Grimson et al. (1953): the removal of all the thoracic and the upper three lumbar ganglia together with the splanchnic nerves and half the coeliac ganglion (7 bilateral cases and 1 unilateral). (2) Adson et al. (1936): the removal of the upper three lumbar ganglia and half the coeliac ganglion together with a short length of the great splanchnic nerve (39 bilateral and 21 unilateral). (3) Smithwick and Thompson (1953): the removal of the lower five thoracic and the upper three lumbar ganglia together with the splanchnic nerves and half the coeliac ganglion (82 bilateral and 17 unilateral). (4) Thoracic : the removal of the lower six to eight thoracic ganglia together with the splanchnic nerves (36 bilateral and 9 unilateral).

In general the more extensive procedures were used for the younger patients in whom symptoms were more evident, and the smaller operations for the older patients. Operations were restricted to one side in 48 patients because of their age or satisfactory symptomatic improvement, or because the disease was thought to be too advanced. Death within six weeks of the date of operation is regarded as an operative death, and this accounts for $4 \%$ of the patients ; two of those who died had an unrecognized phaeochromocytoma.

The severe reduction in blood pressure which occurred for some days after sympathectomy in nearly all the patients produced remarkably little general trouble. One patient suffered colour blindness in one eye which was thought to be a bizarre effect of the post-operative fall in blood pressure. Except in the Adson procedure, the chest was always opened. The common complications of collapse of the contralateral lung and pleural effusion reacted favourably to standard treatment and in no instance persisted. With the thoracic approach post-operative pain was frequent; it appeared about the 10th day, and was felt mildly or severely not only over the wound but also over a large area below it and might last days or weeks. Such pain always disappeared when the other side was operated upon, and often did not occur on the second side. The pain was not the result of damage to an intercostal nerve, for it occurred in $40 \%$ of all sympathectomies, including many in which the surgical approach could not damage somatic nerves.

Postural hypctension was usual during the first few weeks after the second operation, was not altogether related to the persistent fall in blood pressure, and always resolved after a few months. Raynaud's phenomenon appeared in the hands of several patients whose upper thoracic ganglia had been spared; this was irrespective of the effect of the sympathectomy on the blood pressure. Although mostly a minor nuisance, it was severe enough in two patients to call for upper 
thoracic ganglionectomy. Most males from whom the first lumbar ganglia had been removed were rendered impotent. Haematemesis occurred in four men after sympathectomy, but in each there had been evidence of a peptic ulcer before operation. In one of these patients hypertension was found when he presented with haematemesis, and some months after a bilateral Smithwick procedure had been done a duodenal ulcer perforated, showing the typical symptoms and signs, despite the removal of afferent paths for pain. Some dyspepsia recurred after the perforation had been sutured, and eventually partial gastrectomy was performed. Nine years after sympathectomy the patient was in full work and free of symptoms, although the reduction of blood pressure had not been maintained.

\section{Statistics and Results}

Table I shows that the majority of the sympathectomies were performed on patients in the fifth decade, and that there is a preponderance of women. Table II shows that the largest number of operations

TABLE I.-Age and Sex Distribution

\begin{tabular}{ccc|c|c|c}
\hline \multicolumn{2}{c|}{ Age in } & Years & Males & Females & Total \\
\hline $11-20$ & $\ldots$ &. & 0 & 2 & 2 \\
$21-30$ & $\cdots$ & $\cdots$ & 6 & 9 & 15 \\
$31-40$ & $\cdots$ & $\cdots$ & 21 & 30 & 51 \\
$41-50$ & $\cdots$ &. & 47 & 61 & 108 \\
$51-60$ & $\cdots$ &. & 13 & 23 & 36 \\
\hline & & & 87 & 125 & 212
\end{tabular}

TABLE II.-Mortality in Relation to Sex and Pre-operative Group

\begin{tabular}{c|c|c|c|c|c|c}
\hline \multirow{2}{*}{ Group } & \multicolumn{2}{|c|}{ Males } & \multicolumn{2}{c|}{ Females } & Total & Mortality \\
\cline { 2 - 5 } & No. & Deaths & No. & Deaths & No. & \\
\hline 1 & 13 & 1 & 42 & 1 & 55 & $4 \%$ \\
2 & 17 & 4 & 33 & 4 & 50 & $16 \%$ \\
3 & 42 & 21 & 35 & 7 & 77 & $36 \%$ \\
4 & 15 & 14 & 15 & 11 & 30 & $83 \%$ \\
\hline Total & 87 & 40 & 125 & 23 & 212 & $28 \%$ \\
\hline
\end{tabular}

were performed for group 3 patients, and that the expectation of life is greater in women than in men. Of the 22 patients who did not survive the first year after operation, 18 were in group 4 and 4 in group 3. Of the 63 patients who died, cerebrovascular lesions, uraemia, and coronary thrombosis accounted for 43 ; the cause in the remainder is not known. Table III shows the effect of sympathectomy on the blood pressure after the operation, and in the large majority it would

TABLe III.-Effect on Diastolic Pressure After 4-10 Years

\begin{tabular}{c|c|c|c|c}
\hline \multirow{2}{*}{ Group } & \multicolumn{2}{|c|}{ Reduction in Diastolic Pressure } & \multirow{2}{*}{ Total } \\
\cline { 2 - 4 } & $>30 \mathrm{~mm} . \mathrm{Hg}$ & $15-30 \mathrm{~mm} . \mathrm{Hg}$ & $<15 \mathrm{~mm} . \mathbf{H g}$ & \\
\hline 1 & 4 & 10 & 39 & 53 \\
2 & 3 & 4 & 35 & 42 \\
3 & 1 & 13 & 35 & 49 \\
4 & 2 & 3 & 0 & 5 \\
\hline Total & 10 & 30 & 109 & 149 \\
\hline
\end{tabular}

TABLE IV.-Post-operative Changes in the Optic Fundi

\begin{tabular}{|c|c|c|c|c|c|c|}
\hline \multirow{2}{*}{$\begin{array}{c}\text { Pre- } \\
\text { operative } \\
\text { Grado }\end{array}$} & \multirow{2}{*}{$\begin{array}{l}\text { No. of } \\
\text { Cases }\end{array}$} & \multicolumn{4}{|c|}{ Post-operative Grado } & \multirow{2}{*}{$\begin{array}{l}\text { Percentage } \\
\text { Improved }\end{array}$} \\
\hline & & 1 & 2 & 3 & 4 & \\
\hline $\begin{array}{l}1 \\
2 \\
3 \\
4\end{array}$ & $\begin{array}{l}85 \\
66 \\
31 \\
30\end{array}$ & $\begin{array}{r}76 \\
3 \\
3 \\
1\end{array}$ & $\begin{array}{r}9 \\
61 \\
19 \\
5\end{array}$ & $\begin{array}{l}0 \\
2 \\
8 \\
2\end{array}$ & $\begin{array}{r}0 \\
0 \\
1 \\
22\end{array}$ & $\left.\begin{array}{l}70 \\
27\end{array}\right\} 49$ \\
\hline
\end{tabular}

seem that the reduction in blood pressure is not maintained. Table IV shows that the changes in the optic fundi after sympathectomy are most notable in patients with grade 3 fundi.

Symptomatic Results. - Headache previous to sympathectomy was complained of by $90 \%$ of the patients and in almost all of them the operation brought relief ; two-thirds lost their headache completely, and in the others it was less frequent or less severe. The relief of headache continued for a year or more, and in no instance did the headache return to its pre-operative severity. Dizziness before sympathectomy occurred in $50 \%$ of the patients and only $10 \%$ failed to improve after the operation; in half the relief was complete and in the others it was considerable; in $40 \%$ it was maintained. A large proportion of patients complaining of tinnitus gained symptomatic relief, but in no instance was breathlessness assuaged.

\section{Discussion}

Sympathectomy for hypertension carries a low mortality. In 376 operations performed on 212 patients there were nine deaths within six weeks of the operation. All these occurred in groups 3 and 4 , and the selection of patients for operation had included 40 who were extremely ill.

The 10-year survival rate in this series is $66 \%$, and the five-year rate $76 \%$. Smithwick and Thompson (1953), Grimson et al. (1953), and Morrissey et al. (1953) report a five-year survival rate after sympathectomy of 81,77 , and $82 \%$ respectively. The group and sex ratio varies in these different series, but it is reasonable to claim a five-year survival after sympathectomy of 70-80\%. This survival rate compares favourably with that reported by Palmer et al. (1948) in an untreated series. For the purposes of comparison of their series with the present one, patients aged more than 50 years have been omitted from the Palmer series in Table $V$,

TABLE V.-Mortality Compared with an Untreated Sertes

\begin{tabular}{c|c|c|c|c}
\hline \multirow{2}{*}{ Group } & \multicolumn{2}{|c|}{ Palmer et al. (1948) } & \multicolumn{2}{c}{ Present Series } \\
\cline { 2 - 5 } & No. of Cases & Mortality & No. of Cases & Mortality \\
\hline 1 & 68 & $16 \%$ & 55 & $4 \%$ \\
2 & 35 & $43 \%$ & 50 & $16 \%$ \\
3 & 80 & $69 \%$ & 77 & $36 \%$ \\
4 & 45 & $93 \%$ & 30 & $83 \%$ \\
\hline $\begin{array}{c}\text { Years' } \\
\text { observation }\end{array}$ & \multicolumn{2}{|c|}{ Average, 8 } & \multicolumn{2}{|c}{$4-10$} \\
\hline
\end{tabular}

but the 36 aged more than 50 have been left in the present series. Yet, even so, the overall survival in the Palmer series is $49 \%$ and in the present series $70 \%$. The large disparity cannot be explained by the variables within the groups or in sex distribution, and indicates that sympathectomy is of great assistance in prolonging life.

Reduction of the diastolic pressure by $15-45 \mathrm{~mm}$. $\mathbf{H g}$ after sympathectomy occurred in nearly all patients for some weeks or months, but in only $27 \%$ was a reduction of more than $15 \mathrm{~mm}$. $\mathrm{Hg}$ maintained. It was found to be impossible to predict whether the fall in blood pressure after operation would be temporary or sustained. Even in the presence of gross degenerative changes, as for instance grade 3 or even grade 4 fundi, sympathectomy can achieve retrogression of these changes and cause a sustained fall of blood pressure. 
Of the patients showing grade 3 fundi before sympathectomy, $70 \%$ improved, and of those showing grade $4,27 \%$ improved. Death was not delayed many months in patients whose grade 4 fundi remained unchanged by the operation. When improvement in the fundi did occur it was rapid and sustained, even though the initial fall in blood pressure might not be maintained.

The changes in the fundi, the reduction of blood pressure, and the symptomatic relief do not necessarily bear any direct relationship to the extent of the sympathectomy performed, and, as this series progressed, Adson's operation became the usual procedure for patients over 45 years of age who had severe headache. When the effect of this limited sympathectomy was substantial the second side was not done.

Whatever the extent of the sympathectomy performed there was almost always a reduction of blood pressure for some months, and this temporary reduction may be of great importance in permitting hypertrophy of the arteriolar wall, so preventing the arteriolar necrosis of maligant hypertension.

In many hypertensive patients subjected to Adson's operation Raynaud's phenomenon developed in the hands, indicating that sympathectomy exerts a general effect. This general effect may partly explain the improvement in the optic fundus and the increased survival rate after sympathectomy independent of the persistent fall of blood pressure; it is a likely explanation of the dramatic relief of headache by sympathectomy.

The low operative mortality, the $76 \%$ five-year survival rate, the $66 \% 10$-year survival rate; the $27 \%$ rate of sustained reduction in blood pressure, the $49 \%$ rate of improvement in the optic fundi in grades 3 and 4 , and the high rate of symptomatic relief, all point to the justification of sympathectomy as a useful method of treatment for hypertension. The majority of patients returned to work after the operation, kept their jobs, and were able to forget about themselves and their disease for many years.

\section{Summary}

The results of sympathectomy for a period of 4 to 10 years after operation on 212 patients suffering from hypertension are recorded.

The operative mortality was $4 \%$.

The survival rate of $76 \%$ for five years accords with other published records of patients treated by sympathectomy and is in favourable contrast with any published series of patients treated conservatively.

A sustained reduction of diastolic pressure of more than $20 \mathrm{~mm}$. $\mathrm{Hg}$ occurred in $27 \%$.

Retinal improvement occurred in $49 \%$ with severe changes, and when there was no improvement in advanced retinal degeneration death was not long delayed.

Symptomatic relief after sympathectomy was the rule.

Reduction of blood pressure, if only for a few months, may prevent malignant hypertension.

Sympathectomy in hypertension gives many patients an increased expectation of a full and active life.

We thank Professor P. R. Allison, who prompted us to treat patients with hypertension by sympathectomy; Mr. H. T. Simmons, of Manchester, who demonstrated his artistry in performing sympathectomy to us; Mr. G. W.
Black for grading the fundi ; Dr. J. R. H. Towers for making the follow-up in this way possible; and many colleagues who helped us during this period of rapid change in surgery and aftercare.

\section{REFERENCES}

Adson, A. W., Craig, W. McK., and Brown, G. E. (1936). Surg. Gynec. Obstet., 62, 314.

Grimson, K. S., Orgain, E. S., Anderson, B., and D'Angelo, G. J. (1953) Ann, Surg. 138, 532.

Morrissey, D. M., Brookes, V. S., and Cooke, W. T. (1953). Lancet, 1, 403

Palmer, R S., Loofbourow, D., and Doering, C. R. (1948). New Engl. J. Med., 239, 990.

Smithwick, R. H., and Thompson, J. E. (1953). J. Amer. med. Ass., 152, 1501.

Wagener, H. P., and Keith, N. M. (1939). Medicine (Baltimore), 18, 317.

\section{NATURAL HISTORY OF THE PSYCHONEUROSES}

\author{
BY
}

HAROLD E. R. WALLACE, M.B., D.P.M. Deputy Physician-Superintendent, De la Pole Hospital, late Senior Registrar. Scalehor Park Hospital and the Department of Psychiatry, University of Leeds

AND

MARION B. H. WHYTE, M.A.

Senior Psychiatric Social Worker and Tutor, Department of Psychiatry, University of Leeds

The natural history of the neuroses is a topic which has been little reported on, although its importance as a standard against which the efficacy of treatment can be assessed is only too obvious.

The University Department of Psychiatry was opened in the General Infirmary at Leeds in 1946, and the demand for its services soon exceeded the clinic's capacity. As a result there accumulated a list of psychoneurotic patients awaiting psychotherapy, and by 1955 this list had risen to 83 patients, some of whom had been waiting for seven years. This situation offered an opportunity of studying the extent to which such patients show a tendency to spontaneous recovery.

\section{Method}

The first step was to classify the patients, and, since no "standard system" had been in use in the clinic, our classification was based on our reading of the notes. It became clear that there were three groups of patients: (1) Those in whom the symptoms were predominantly overt anxiety. These were classed as " anxiety state" (42 patients). (2) Those who suffered from hysterical conversion symptoms. These were classed as "hysteria" (19 patients). (3) Those who did not fall into either group 1 or 2 . These were classed as "miscellaneous" (22 patients), and comprised the following diagnoses: depression, 5 ; hypochondriasis, 4 ; schizoid personality, 4 ; stammer, 3 ; psychopathic personality, 2 ; obsessional neurosis, 1 ; eczema, 1 ; impotence, 1 ; homosexuality, 1.

A letter was sent to each patient saying that the department was interested in how he was progressing (no mention was made of the fact that the promised treatment had not been forthcoming), and the choice of a home visit or interview at the clinic was offered.

The result of this inquiry was that 29 patients agreed to be interviewed, 15 refused to be interviewed, 13 letters were returned marked "unknown," from 20 there was 